\title{
Adenosquamous carcinoma of the pancreas, a rare tumor entity: a
}

\section{case report}

\author{
Pavlos Lampropoulos*1, Georgios Filippou ${ }^{1}$, Evangelia Skafida ${ }^{2}$, \\ Thivi Vasilakaki ${ }^{2}$, Nikolaos Paschalidis ${ }^{1}$ and Spiros Rizos ${ }^{1}$
}

\author{
Address: ${ }^{1}$ Department of General Surgery, Piraeus General Hospital "Tzaneio", Afentouli \& Tzani Str, Piraeus-Athens, 16345, Greece and \\ 2Department of Pathogical and Anatomical, Piraeus General Hospital "Tzaneio", Afentouli \& Tzani Str, Piraeus-Athens, 16345, Greece \\ Email: Pavlos Lampropoulos* - pav.lampropoulos@gmail.com; Georgios Filippou - geo.filippou@gmail.com; \\ Evangelia Skafida - EvelinaSkafida@hotmail.com; Thivi Vasilakaki - thvasilakaki@yahoo.gr; Nikolaos Paschalidis - n-pasxal@otenet.gr; \\ Spiros Rizos - srizos@otenet.gr \\ * Corresponding author
}

Published: 2 December 2009

Cases Journal 2009, 2:9129 doi:10.1186/1757-1626-2-9129

This article is available from: http://www.casesjournal.com/content/2/I/9129

(C) 2009 Lampropoulos et al; licensee BioMed Central Ltd.

This is an Open Access article distributed under the terms of the Creative Commons Attribution License (http://creativecommons.org/licenses/by/2.0), which permits unrestricted use, distribution, and reproduction in any medium, provided the original work is properly cited.
Received: 5 November 2009

Accepted: 2 December 2009

\begin{abstract}
Introduction: Adenosquamous carcinoma of the pancreas is a rare variant of exocrine pancreatic tumor. This type of tumor is extremely rare as only few similar cases have been described in the literature.

Case presentation: We present a case of a 72 years old male patient who was admitted to the hospital complaining of epigastric pain and jaundice. Pancreatic carcinoma of the head was diagnosed and a pylorus preserving pancreaticoduodenectomy was performed.

Conclusion: This type of cancer is a very aggressive tumor followed by a dismisal prognosis. Multimodality therapy seems to be a reasonable approach but more studies are needed, to propose the most effective treatment.
\end{abstract}

\section{Introduction}

Pancreatic cancer is the 6th leading cause of death in Europe, while the incidence rate approaches the mortality rate [1]. Adenosquamous carcinoma is a rare entity of pancreatic cancer. Institutional reviews of autopsy and surgical specimens suggest an incidence of approximately $4 \%$ of all pancreatic neoplasms. It has been variously referred to as adenoacanthoma, mixed squamous and adenocarcinoma, and mucoepidermoid carcinoma. Only a few cases, 150 approximately, have been reported in the accessible literature, until 2008 [2]. Largest series published are from Rahemtullah et al and Kardon et al, with 14 and 25 cases respectively $[3,4]$.

\section{Case presentation}

A 72-years-old Caucasian Greek male patient presented with epigastric pain of low intensity, jaundice and loss of appetite for the past 30 days. The patient was a heavy smoker (50 cig/day) and consumed alcohol (wine) occasionally, in small quantities. Physical examination revealed a distressed male patient with a body temperature of $37^{\circ} \mathrm{C}$, blood pressure of $130 / 85 \mathrm{mmHg}$ and pulse rate about $85 / \mathrm{min}$. Painless jaundice was the presenting symptom and Courvoisier sign was present. The patient had no sings of ascites, or gastrointestinal obstruction. Hematocrit was $31 \%$, white blood cells $10630 / \mu \mathrm{L}$ with neutrophil prevalence $77 \%$ and platelets $341.000 / \mu \mathrm{L}$. Biochemical profile showed Tbil: $7.50 \mathrm{mg} / \mathrm{dl}$, Dbil: $5.50 \mathrm{mg} /$ 
dl, SGOT: 109 U/L, SGPT: 145 U/L, $\gamma$ GT: 517 U/L, ALP: 467 U/L, LDH: 503 U/L, CA125: 244, 50 U/L, CA19.9: $51.30 \mathrm{U} / \mathrm{L}$. The patient was receiving digoxin and warfarin for chronic atrial fibrillation. Thin section computer tomography showed dilatation of the gallbladder and intra/ extrahepatic biliary tree, while a $5 \mathrm{~cm}$ mass of the uncinate process of the pancreas was identified to invade the intrapancreatic portion of the bile duct, as well as the $2^{\text {nd }}$ and $3^{\text {rd }}$ portion of the duodenum (Figure 1). There was no extrapancreatic disease, no extension to the superior mesenteric artery and celiac axis. The superior mesentericportal confluence was patent. The decision for surgical intervention was taken, and a pylorus preserving pancreaticoduodenectomy was performed after exploratory laparoscopy. The patient had an uneventful postoperative course and discharged on the $11^{\text {th }}$ day.

Histological evaluation of the pancreatic tumor showed an adenosquamous carcinoma which was extensively infiltrative with perineural invasion, involvement of peripancreatic lymph nodes and all the thickness of the duodenum wall. The tumor elicited an intense desmoplastic stromal reaction and areas of necrosis (Figure 2). Focal areas of high grade pancreatic intraepithelial neoplasia were seen. The tumor exhibited a biphasic malignant growth identified as, well to moderate differentiated adenocarcinoma and well to poorly differentiated squamous cell carcinoma (Figure 3). The adenocarcinoma component contained ductal or glandular structures with focal intracellular or extracellular mucin (Figure 4). Squamous differentiation was characterized by irregular and infiltrative nests or sheets of polygonal cells with distinct cellular borders, intercellular bridges, eosiniphilic cytoplasm and varying degrees of keratinization (Figure 5). These two different patterns could be seen separated topographically within the substance of the tumor or intimately admixed. Six of the 15 resected lymph nodes were positive for met-

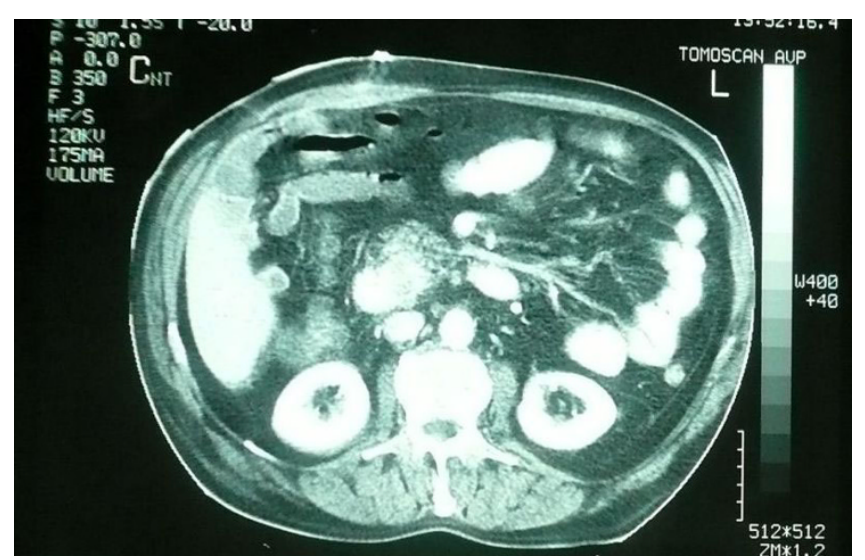

Figure I

CT scan of the patient showing the tumor.

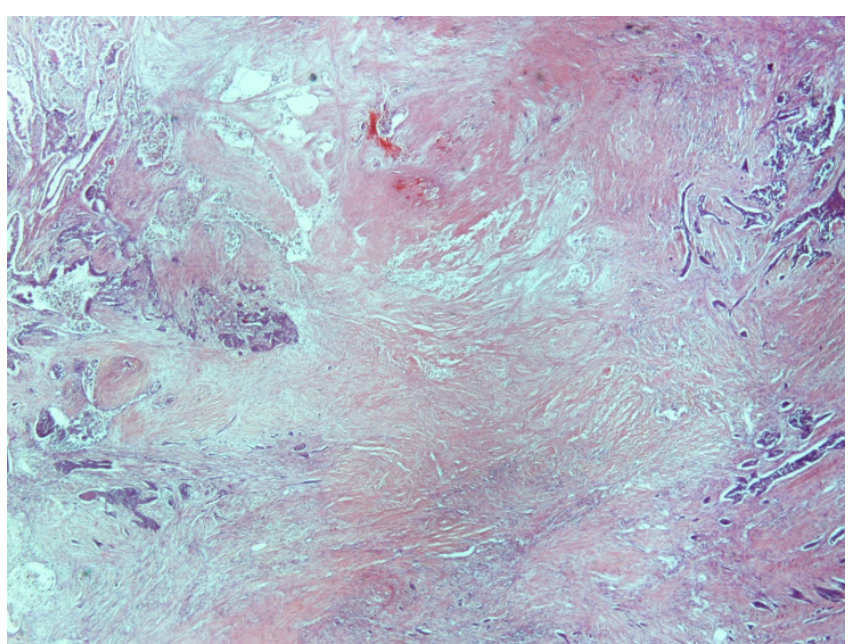

Figure 2

$($ H\&E $\times 20)$ Adenosquamous carcinoma of the pancreas with area of necrosis.

astatic tumor which was composed of squamous carcinoma only (Figure 6).

The immunohistochemical study showed that the tumor cells were positive for cytokeratin AE1 and AE2. Cam 5.2 and Ker 7 were reactive predominantly in the adenocarcinoma component and in few squamous cells (Figure 7). Immunoreactivity for CK 5/6 was restricted to the squamous component, while the glandular component was negative (Figure 8). A few number of tumor cells were immunoreactive with CEA and Ca 19-9. All tumor cells were negative for Ker 20, chromogranin and synaptophysin.

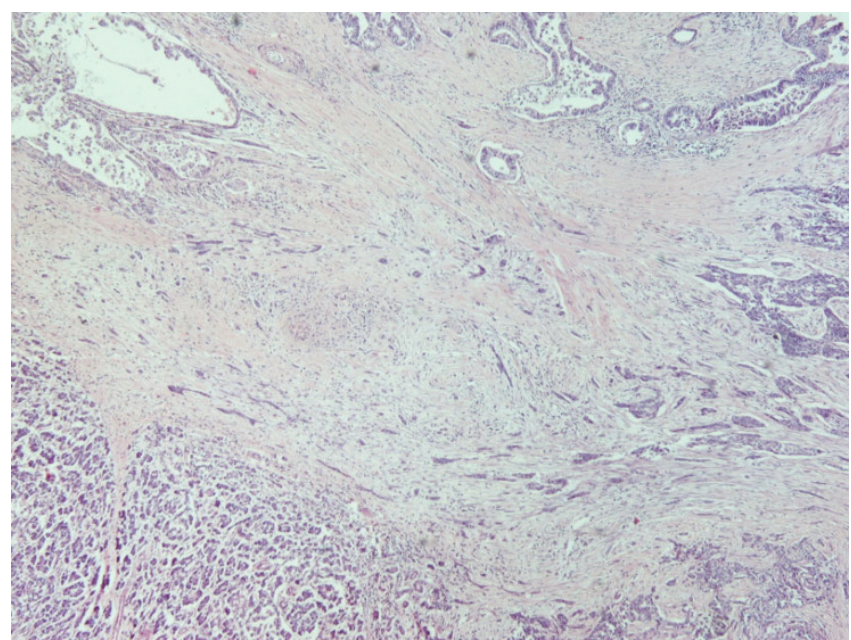

Figure 3

(H\&E ×40) Adenosquamous carcinoma of the pancreas. 


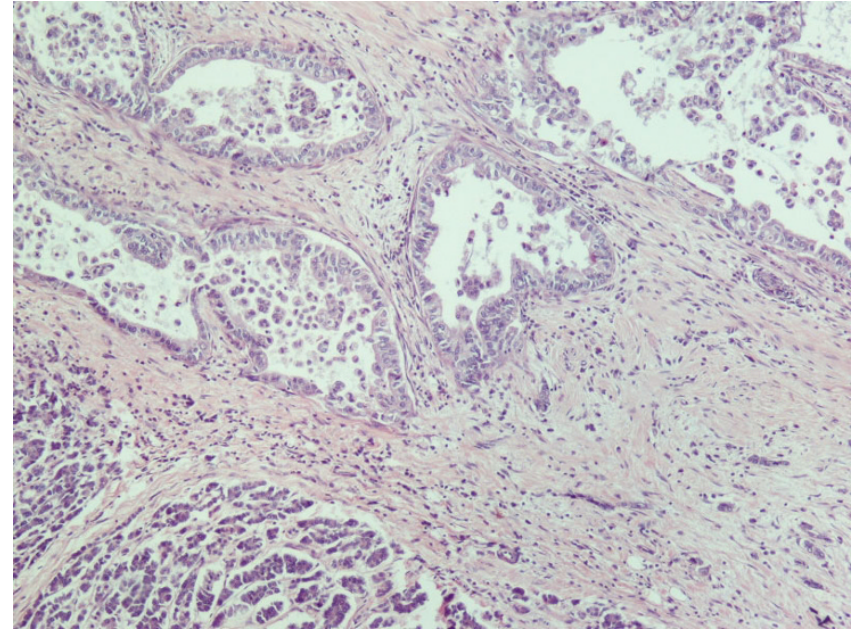

Figure 4

$(H \& E \times 100)$ Adenocarcinoma similar to ductal carcinoma.

The patient received adjuvant therapy (5-FU in combination with radiation). He received 40 Gy in two 20 - Gy courses and $500 \mathrm{mg}$ per $\mathrm{m}^{2} 5$-FU by intravenous bolus delivered daily for the initial 3 days of each radiation course and then weekly. The patient 24 months postoperatively, remains disease free.

\section{Discussion}

The incidence of adenosquamous carcinoma of the pancreas ranges among studies from 3\% [5] to $11.1 \%$ [6], however the true incidence is not known since this is an aggressive tumor and most patients have not undergone

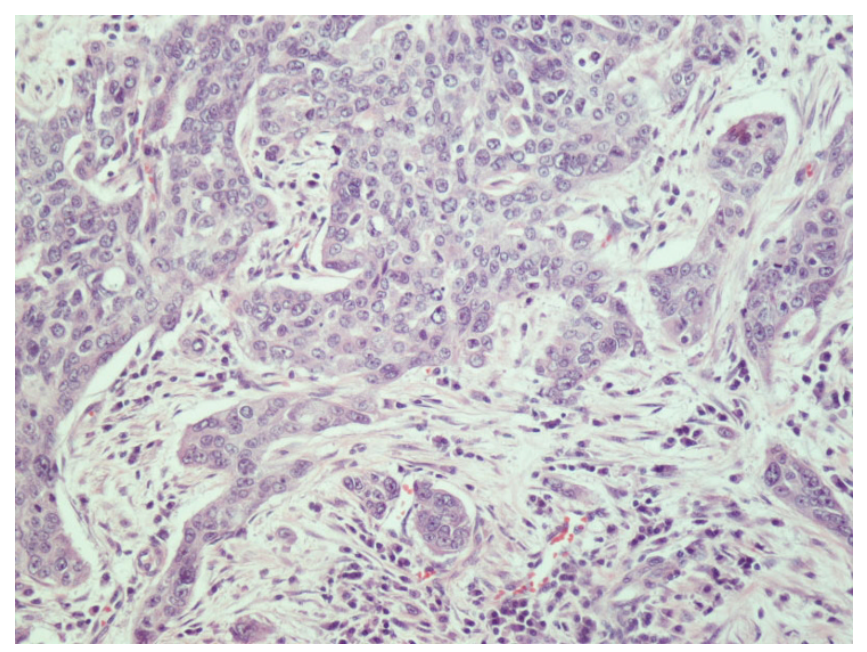

Figure 5

(H\&E $\times 200)$ Squamous cell carcinoma composed of irregular nests of polygonal cells with no gland formation.

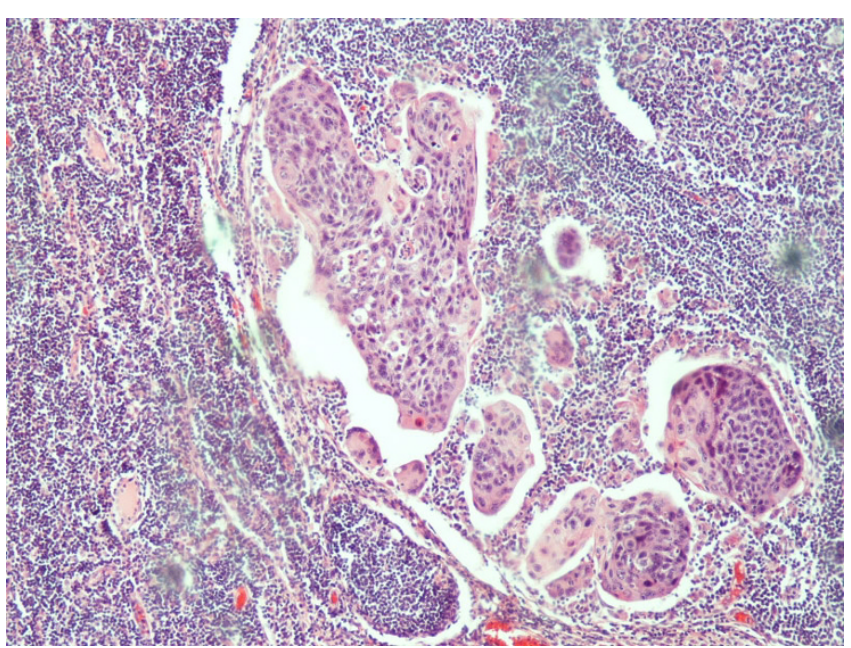

\section{Figure 6}

(H\&E x 100) Lymph node metastasis only from the squamous element.

surgery or autopsy. A few theories have been reported concerning the formation of adenosquamous carcinoma in an organ, where almost exclusively adenocarcinoma is the predominant cancer involved. One such theory postulates that a metaplastic squamous epithelium undergoes malignant transformation. Additionally, a preexisting adenocarcinoma could undergo malignant change and finally, a primitive cell may be capable of differentiating to either squamous or adeno component [6].

Preoperative diagnosis is often difficult, as there are no specific characteristics that can identify the squamous component in the lesion. However, Ga-67 citrate scintig-

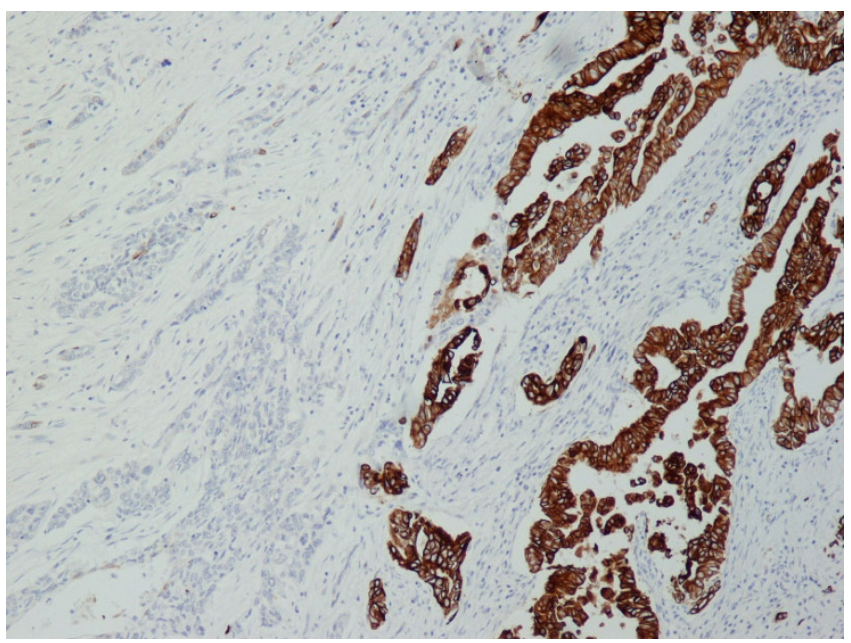

Figure 7

$($ Ker7 $\times 100)$ Ker7 showed predilection for adenocarcinoma. 


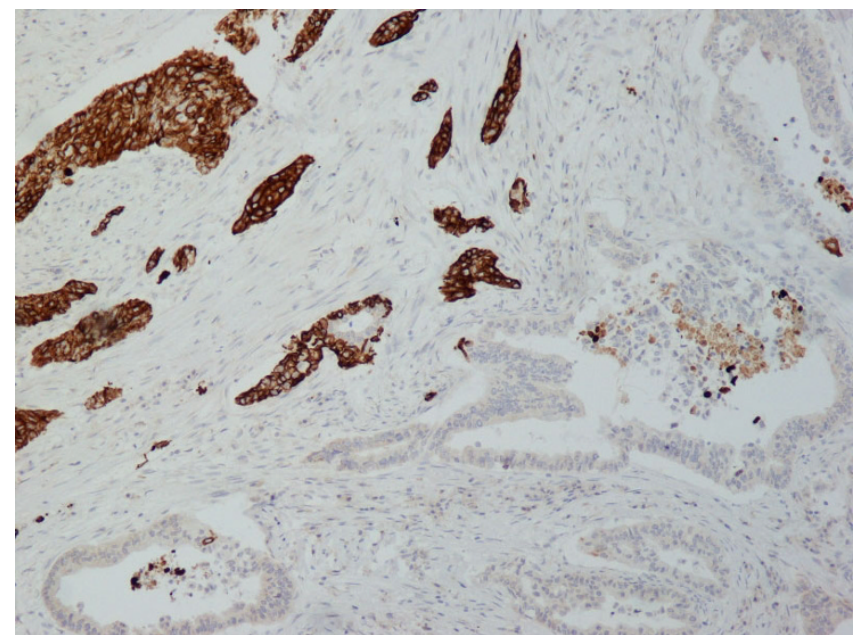

Figure 8

$($ CK5/6 $\times 100)$ The squamous component was strongly immunoreactive with $\mathrm{CK} 5 / 6$, while the glandular component was negative.

raphy may be useful in detecting adenosquamous carcinoma of the pancreas [7]. On CT imaging, features suggestive of adenosquamous carcinomas of the pancreas include large infiltrative lesions and the presence of central necrosis [8]. Nabae et al. concluded that the presence of central necrosis in an infiltrative huge pancreatic tumor seems to be suggestive of the diagnosis of adenosquamous carcinoma of the pancreas [9]. The role of endoscopic US-guided FNA biopsy remains controversial.

Once the diagnosis is established either preoperative or postoperative, the question that rises refers to the best treatment modality for this aggressive tumor of the pancreas. From the literature reviewed, there is no study with significant statistical power to address that question. Smoot et al. demonstrated a longer survival for patients that can undergo an R0 resection. For R0 resection median survival was 14.4 months compared to 8 months for R1 and 4.8 months for patients undergoing palliative therapies [10]. Hsu JT et al. showed that the cumulative survival rates of 12 patients with pancreatic adenosquamous carcinomas, ranged from 1.12 to 22.42 months, with a median of 4.41 months. Additionally, patients with pancreatic adenosquamous carcinomas had shorter median survival compared to those with adenocarcinoma 6.51 months vs. 9.76 months [11]. Multidisciplinary treatments including aggressive surgery, intraoperative radiation therapy, and locoregional chemotherapy have also been reported to improve the survival of patients with adenosquamous carcinoma of the pancreas and to inhibit liver metastasis and local recurrence [12]. Shibagaki K et al. presented a case of successful use of chemoradiotherapy with low-dose cispastin and additional combined chemotherapy with S-1 and cisplatin for unresectable pancreatic adenosquamous carcinoma [13]. Tanaka $\mathrm{N}$ et al. suggested that combined chemotherapy with cytokines (IFN-a plus TNF-a) and 5FU may be a therapeutic modality for advanced pancreatic cancer [14]. Wilkowski $R$, et al. concluded that gemcitabine and cisplatin can safely be combined with external beam radiation. This preoperative treatment approach is highly effective and appears to improve survival in patients whose tumors are rendered completely resectable [15]. However, there have been no sufficient studies that could propose a treatment modality for this rare tumor.

\section{Conclusion}

It has become clear that this type of cancer has a dismissal prognosis. Even with aggressive therapies median survival is poor. More studies are needed to address the role of surgery and the use of adjuvant therapy, however this is quite difficult as this tumor entity is extremely rare. Since squamous cell carcinomas seem to respond satisfactory to chemoradiotherapy regimens based on 5-FU, this combination could be potentially used as adjuvant therapy in patients with resectable squamous cell pancreatic cancer, or as palliative therapy for unresectable tumors. R0 resection remains the gold standard for those individuals who are fit enough to undergo such a major operation.

\section{Consent}

Written informed consent was obtained from the patient for publication of this case report and any accompanying images. A copy of the written consent is available for review by the Editor-in-Chief of this journal.

\section{Competing interests}

The authors declare that they have no competing interests.

\section{Authors' contributions}

PL participated in the patient's treatment, made the literature search, contributed in the writing and the revision of the draft. GF contributed in the literature search, co wrote the draft and made the revision. ES carried out the pathological examination and contributed in the writing of the draft. TV participated in the diagnosis of the case and in the presentation of its pathology, contributed in the pathological examination and in the revision of the draft. NP participated in the patient's treatment, had the concept and the coordination of the case report and contributed in the revision. SR contributed in the revision and had the final approval of the draft. All authors read and approved the final manuscript.

\section{Acknowledgements}

The writers would like to thank Mrs E. Karzi, radiologist for her contribution to the preoperative evaluation and diagnosis of the patient. They would also like to thank the patient for his written consent.

\section{References}

I. Michaud DS: Epidemiology of Pancreatic Cancer. Minerva Chir 2004, 59:99-III. 
2. Madura JA, Jarman BT, Doherty MG, Yum MN, Howard TJ: Adenosquamous Carcinoma of the Pancreas. Arch Surg 1999, 134:599-603.

3. Rahemtullah A, Misdraji J, Pitman MB: Adenosquamous carcinoma of the pancreas: cytologic features in 14 cases. Cancer 2003, 99:372-378.

4. Kardon DE, Thompson LD, Przygodzki RM, Heffess CS: Adenosquamous carcinoma of the pancreas: a clinicopathologic series of 25 cases. Mod Pathol 200I, I 4:443-45I.

5. Cubilla AL, Fitzgerald PJ: Morphological Lesions Associated With Human Primary Invasive Nonendocrine Pancreas Cancer. Cancer Res 1976, 36:2690-2698.

6. Ishikawa O, Matsui Y, Aoki I, Iwanaga T, Terasawa T, Wada A: Adenosquamous Carcinoma of the Pancreas: A Clinicopathologic Study and Report of Three Cases. Cancer 1980, 46:1192-3196

7. Kuji I, Sumiya H, Taki J, Nakajima K, Yokoyama K, Kinuya S, Kinuya K Ichikawa A, Konishi S, Michigishi T, Tonami N: Intense Ga-67 Uptake In Adenosquamous Carcinoma Of The Pancreas. Ann Nucl Med 1997, I I:4 I-43.

8. Zhang B, Gao SL: Education of imaging. Hepatobiliary and pancreatic: adenosquamous carcinoma of the pancreas. J Gastroenterol Hepatol 2008, 23:820.

9. Nabae T, Yamaguchi K, Takahata S, Utsunomiya N, Matsunaga $H$ Sumiyoshi K, Chijiiwa K, Tanaka M: Adenosquamous carcinoma of the pancreas: report of two cases. Am J Gastroenterol 1998 93:1167-II70

10. Smoot RL, Zhang L, Sebo TJ, Que FG: Adenosquamous carcinoma of the pancreas: a single-institution experience comparing resection and palliative care. J Am Coll Surg 2008 207:368-370.

II. Hsu JT, Chen HM, Wu RC, Yeh CN, Yeh TS, Hwang TL, Jan YY, Chen MF: Clinicopathologic features and outcomes following surgery for pancreatic adenosquamous carcinoma. World J Surg Oncol 2008, 6:95.

12. Yamaue H, Tanimura $H$, Onishi $H$, Tani M, Kinoshita $H$, Kawai $M$, Yokoyama S, Uchiyama K: Adenosquamous carcinoma of the pancreas: successful treatment with extended radical surgery, intraoperative radiation therapy, and locoregional chemotherapy. Int J Pancreatol 200I, 29:53-58.

13. Shibagaki K, Fujita K, Nakayama S, Takenaka M, Fukuba N, Matsui S, Ozaka M, Yoshinaga $H$, Masuzawa A, Watanabe A, Fujiwara $H$, Sugawara A, Fujita $T$, Mukai $H$, Kinoshita $Y$ : Complete response of a pancreatic adenosquamous carcinoma to chemoradiotherapy. Int I Clin Oncol 2008, 13:74-77.

14. Tanaka N, Ohoida J, Matuno T, Gouchim A, Iwagaki H, Moreira LF, Orita K: Response of adenosquamous carcinoma of the pancreas to interferon-alpha, tumor necrosis factor-alpha and 5fluorouracil combined treatment. Anticancer Res 1994, I 4:2739-2742.

15. Wilkowski R, Thoma M, Schauer R, Wagner A, Heinemann V: Effect of chemoradiotherapy with gemcitabine and cisplatin on locoregional control in patients with primary inoperable pancreatic cancer. World J Surg 2004, 28:1011-1018.

Publish with Bio Med Central and every scientist can read your work free of charge

"BioMed Central will be the most significant development for disseminating the results of biomedical research in our lifetime. "

Sir Paul Nurse, Cancer Research UK

Your research papers will be:

- available free of charge to the entire biomedical community

- peer reviewed and published immediately upon acceptance

- cited in PubMed and archived on PubMed Central

- yours - you keep the copyright
BioMedcentral 